\title{
Outcome of Core Out Fistulectomy and the Ligation of Anal Fistula Tract: A Single Center Experience in Malaysia
}

\author{
M Salehudin C. $Z^{a}$, Azmi M. Nor ${ }^{b}$, R Mohd Rus ${ }^{c}$ \\ ${ }^{a}$ Department of Surgery, Hospital Tengku Ampuan Afzan, Kuantan, Pahang \\ ${ }^{\mathrm{b}}$ Colorectal Unit, Department of Surgery, Faculty of Medicine, International Islamic University Malaysia, \\ Kuantan, Pahang \\ 'Department of Community Medicine, Faculty of Medicine, International Islamic University Malaysia, Kuantan, \\ Pahang
}

Introduction: Fistula-in-ano is a benign anorectal disease which always poses a big dilemma to the surgeons because of their significant recurrent rate following surgery. Materials and Methods: A cross-sectional study involving 42 patients undergoing core out fistulectomy in the Hospital Tengku Ampuan Afzan, Kuantan, Pahang, Malaysia were included in this study. Demographic data of patients were assessed. Endoanal ultrasound (EAUS) was done prior to the surgery to determine types of fistula and classified using Park's classification. Follow up was made post-operatively at $4^{\text {th }}$ week, $2^{\text {nd }}$ month, $3^{\text {rd }}$ month, $4^{\text {th }}$ month, $5^{\text {th }}$ month and $6^{\text {th }}$ month to look for the duration of healing or recurrence. Results: 5 out of 42 patients were lost to follow up leaving 37 patients available for the analysis. Mean age of the patient was 38.4 (13.8) years old. Transphincteric and intersphincteric type of fistula accounted for $54.5 \%$ and $40.1 \%$, respectively. $62.2 \%$ $(n=23)$ of patients achieved primary healing after the procedure. The mean for healing duration was 3.7 (3.1) months. Recurrence of the disease was seen only in $37.8 \%(n=14)$ of the patients. Conclusions: Even though we managed to achieve significant success rate cumulatively, recurrence of fistula still impose a significant challenge toward patient's management. Therefore, further prospective study with a bigger sample size is recommended to look into this method to reduce recurrence of fistula.

KEYWORDS: Fistula-in-ano, Anal fistula, Core out fistulectomy.

\section{INTRODUCTION}

Fistula in ano is a benign anorectal condition and is commonly cryptoglandular in origin. ${ }^{1}$ It occurs as a result of obstruction of the cryptoglandular duct, infection and subsequently forming an abscess collection. ${ }^{2}$ In general, the incidence of fistula in ano is around 9 per 100,000 population. ${ }^{3}$ Incidence in male gender is about 12.3 per 100,000 population and in female is about 5.6 per 100,000 respectively. ${ }^{4}$ Fistula in ano usually occurs during the third and fourth decades of life. ${ }^{5}$ Mediterranean, Middle East and Indian subcontinent show higher incidence of fistula in ano. ${ }^{5}$ Park's classification ${ }^{6}$ is used to

Corresponding author:

Prof. Dr. Azmi Md. Nor

Colorectal Unit, Department of Surgery,

Kulliyysah of Medicine,

International Islamic University Malaysia,

Kuantan, Pahang

Tel No :+6095704401

Email : azmimn@iium.edu.my determine the types of fistula in ano: intersphincteric, transphincteric, suprasphincteric and extrasphincteric. 'Complex fistula' is a term referred to the following features: recurrent fistula, fistula due to local irradiation, fistula in Crohn's disease, fistula with multiple tracts or preexisting incontinence. $^{7}$

The aim of management in any fistula-in-ano cases would include includes sepsis control, fistulous tract closure, preservation of continence, and avoiding recurrence. ${ }^{3,5}$ Currently, there are many operative and non-operative procedures being introduced in the treatment of fistula in ano. These include fistulotomy, core fistulectomy, anorectal advancement flap, ligation of intersphincteric fistulous tract (LIFT), seton applications, fibrin glue injection, anal fistula plug, video assisted anal fistula treatment (VAAFT) and fistula laser closure (FiLaC ${ }^{T M}$ ). Each of these methods carry its own morbidity particularly recurrence rates and fecal incontinence. ${ }^{7}$ 
It has been reported that treatment of low lying fistula with laid open fistulotomy has a recurrence rate of about $8 \%$ and approximately $45 \%$ are reported to have some degree of incontinence. ${ }^{8}$ Up to $35 \%$ of incontinence was observed after the transanal advancement flap procedure. ${ }^{9}$ Tight seton application also carried significant incontinence rates as high as 63\%. However, recurrence in the seton application was observed only in $6 \% .^{10} \mathrm{~A}$ systematic review with regard to fibrin glue in treating the fistula-in-ano showed overall healing rate of $53 \%$. No incontinence was observed as this technique did not cause any trauma to the anal sphincter. ${ }^{11}$ A combination of limited fistulectomy and fibrin glue injection in complex fistula in ano had shown healing of the disease in $86 \%$ of patients. ${ }^{12}$ Treatment of fistula-in-ano with LIFT technique had achieved primary healing in $82.2 \%$ of patients and no incontinence was noted. ${ }^{7}$

Other than the surgical approaches described previously other factors that has associated with recurrence includes complex type of fistula, horseshoe extension, lack of identification or lateral location of the internal fistulous opening, previous fistula surgery, and also the experience of the surgeon performing the procedure. ${ }^{8}$

The aims of this study are to identify the demography of the patients, types of fistula, duration of healing and factors associated with recurrence from core out fistulectomy and ligation of anal fistula tract in the management of fistula-inano.

\section{METERIALS AND METHOD}

\section{Methodology}

A cross-sectional study involving 42 patients was conducted at Hospital Tengku Ampuan Afzan, Kuantan, Pahang, Malaysia between January 2011 and June 2016. All patients presented with fistula-inano caused by cryptoglandular infection were included and evaluated in the study. Patients with fistula-in-ano secondary to such as rectovagival fistula, Crohn's fistula, or fistula caused by Tuberculosis were excluded.

All patients underwent endoanal ultrasound (EUS) assessment prior to the surgery. Endoanal ultrasound was done by certified and accredited colorectal surgeons using the 2052 endoanal ultrasound probe from the BK Medical.

The patients were admitted one day prior to the procedure. The operation was performed under spinal anaesthesia and patients were placed in the prone jack-knife position. Prophylactic intravenous antibiotic consisted of intravenous cefoperazone 1 gm and intravenous metronidazole 500 mg. Fistula tract and the internal opening were identified by gentle probing using Lockhart Mummary Fistula Probe. Injection of 1-2 $\mathrm{ml}$ of $20 \%$ hydrogen peroxide using a 20G branula through the external opening was utilized when probing failed. Eisenhimmer Rectal Speculum was introduced prior to the injection of the hydrogen peroxide. Incision was made around the external opening by using diathermy and cored until reaching the anal sphincter complex. The cored tract was transfixed and ligated using absorable suture with vicryl $3 / 0$. It was then divided and sent for histopathological examination.

After discharge, the patients were advised to take sitz baths (warm salt water) for about 15-20 minutes daily. All patients were followed up every 2 weeks for one month and then monthly for another 5 months. Primary wound healing is defined as complete epithelialization of the wound. Recurrence is defined as a non-healing wound or reappearance of an external opening with persistent discharge. Absence of acute or chronic symptoms on follow-up was considered as cure. ${ }^{7,13}$

The data collected were analysed using IBM SPSS Statistics version 20 (IBM Corp., Armonk, NY). Categorical variables were expressed as frequency and percentage. Numerical data was presented as mean and standard deviation in normally distributed data and median and IQR in not normally distributed data. Chi square test was used to analyse association between categorical variables. P-value < 0.05 is considered as statistically significance.

Ethical approval was obtained from IIUM Research Ethics Committee (IREC) (ref no: IUM/305/14/11/2, IREC No: 299). Written informed consent was obtained from each of the patients before the operation.

Only 37 out of 42 patients were available for analysis. Five patients were lost to follow up. Mean 
age of patients with fistula in ano in this study were found to be 38.4 (13.8) years old. Majority of the patients were males $(83.8 \%)$. Malays $(86.4 \%)$ were the majority affected, followed by Chinese $(10.8 \%)$ and Indian $(2.7 \%)$ respectively. Almost a quarter of patients $(24.3 \%)$ had co-morbidities such as diabetes mellitus, hypertension, ischaemic heart disease and asthma. More than half of the cases $(54.1 \%)$ is of the transphincteric type followed by intersphincteric $(40.5 \%)$ and subsequently $(2.7 \%)$ in each of extrasphinteric and low fistula type. $64.9 \%(n=24)$ of the cases were new cases and primary healing was achieved in $62.2 \%$ of the patients. Duration of healing was 3.7 (3.1) months (Table 1).

\section{RESULT}

Only 37 out of 42 patients were available for analysis. Five patients were lost to follow up. Mean age of patients with fistula in ano in this study were found to be 38.4 (13.8) years old. Majority of the patients were males $(83.8 \%)$. Malays $(86.4 \%)$ were the majority affected, followed by Chinese $(10.8 \%)$ and Indian (2.7\%) respectively.

Almost a quarter of patients $(24.3 \%)$ had comorbidities such as diabetes mellitus, hypertension, ischaemic heart disease and asthma. More than half of the cases $(54.1 \%)$ is of the transphincteric type followed by intersphincteric $(40.5 \%)$ and subsequently $(2.7 \%)$ in each of extrasphinteric and low fistula type. $64.9 \%(n=24)$ of the cases were new cases and primary healing was achieved in $62.2 \%$ of the patients. Duration of healing was 3.7 (3.1) months (Table 1).

There was no significant difference in the recurrence of the disease between males and females $(p=0.761)$. Ethnicity also did not significantly $(p=0.176)$ influence wound healing. Athough the transphincteric fistula was the most common type seen, there was no significant difference in term of the rate of healing $(p=0.28)$. There was no difference in the rate of healing between the newly diagnosed cases or recurrent cases after surgery $(p=0.954)$ (Table 3$)$.

In this study almost two third $(62.2 \% ; n=23)$ of patients the fistula were healed after core out fisulectomy and the ligation of fistula tract. Anal fistula always pose a challenging surgical problem of recurrence after surgery. The rate of recurrence depends on the type of procedure performed for the
Table 1: Socio-demographic characteristics \& duration of healing in patients with fistula in ano $(n=37)$

\begin{tabular}{|c|c|}
\hline Variables & No. (\%) \\
\hline Age (years) & $38.4(13.8)^{*}$ \\
\hline \multicolumn{2}{|l|}{ Gender } \\
\hline Male & $31(83.8)$ \\
\hline Female & $6(16.2)$ \\
\hline \multicolumn{2}{|l|}{ Ethnicity } \\
\hline Malay & $32(86.5)$ \\
\hline Chinese & $4(10.8)$ \\
\hline Indian & $1(2.7)$ \\
\hline \multicolumn{2}{|l|}{ Comorbidities } \\
\hline Yes & $9(24.3)$ \\
\hline No & $28(75.7)$ \\
\hline \multicolumn{2}{|l|}{ Types of fistula } \\
\hline Transphincteric & $20(54.1)$ \\
\hline Intersphincteric & $15(40.5)$ \\
\hline Extrasphincteric & $1(2.7)$ \\
\hline Low Fistula & $1(2.7)$ \\
\hline \multicolumn{2}{|l|}{ Type of Cases } \\
\hline New & $24(64.9)$ \\
\hline Recurrent & $13(35.1)$ \\
\hline Duration of healing (months) & $3.7(3.1)^{*}$ \\
\hline
\end{tabular}

* Mean (SD)

anal fistula. In a study done by Tobisch A et al. the anal fistula healed in $74 \%$ of the patients. ${ }^{14} \mathrm{~A}$ study done by Paiboon $\mathrm{J}$ on core out fistulectomy and combine with anal sphincter reconstruction and primary repair of internal opening showed $87.9 \%$ $(n=29)$ of fistula healed ${ }^{15}$ We believed the ligation of the cored fistula tract before dividing it. blocked fecal material from entering into the wound through the internal opening.

Successful surgical treatment of fistula-in-ano depends on the accuracy in identifying the types of anal fistula and its anatomy. We used endoanal ultrasound (EUS) to assess the anal fistula. EUS demonstrates the types of fistula, the length and presence secondary tract. Presence of abscess can also be demonstrated. Hydrogen peroxide was injected through the external opening to facilitate visualization of the fistula. In this study transphincteric and intersphincteric anal fistulas were found in $54.1 \% \quad(n=20)$ and $40.5 \% \quad(n=15)$, respectively. 
Table 2 Outcome of core fistulectomy

\begin{tabular}{lc}
\hline & Number of patient (\%) \\
\hline Healed & $23(62.2)$ \\
Recurrent & $14(37.8)$ \\
\hline
\end{tabular}

Recurrence occurred in $37.8 \%(n=14)$ patients in this study. However, gender, ethnic, types of fistula and types of cases did not statistically significant in influencing healing and recurrence of fistula. In a study done by Kronborg 0 on 47 patients patients with fistula-in-ano, fistula recurred in only $9.52 \%$ $(n=2)$ patients treated with fistulectomy. ${ }^{16}$ This was very much lower compared to our study. However, there was anal incontinence reported in patients treated with fistulectomy. ${ }^{16}$

Table 3 The analyses of surgical outcomes for core out fistulectomy $(n=37)$

\begin{tabular}{|c|c|c|c|c|}
\hline Factors & $\begin{array}{l}\text { Healed } \\
(n=23)\end{array}$ & $\begin{array}{l}\text { Surgical } \\
\text { Out- } \\
\text { comes }\end{array}$ & $\begin{array}{l}\text { Recurrent } \\
(n=14)\end{array}$ & $\begin{array}{l}\mathrm{P} \\
\text { value* }^{*}\end{array}$ \\
\hline Gender & & & & 0.761 \\
\hline Male & 19 & & 11 & \\
\hline Female & 4 & & 3 & \\
\hline Ethnicity & & & & 0.176 \\
\hline Malay & 21 & & 11 & \\
\hline Chinese & 2 & & 1 & \\
\hline Indian & 0 & & 2 & \\
\hline Types of Fistula & & & & 0.28 \\
\hline Transphincteric & 14 & & 6 & \\
\hline Intersphincteric & 9 & & 6 & \\
\hline Extrasphincteric & 0 & & 1 & \\
\hline Low Fistula & 0 & & 1 & \\
\hline Type of Cases & & & & 0.954 \\
\hline New & 15 & & 9 & \\
\hline Recurrent & 8 & & 5 & \\
\hline
\end{tabular}

${ }^{*}$ chi-square test

Core out fistulectomy and the ligation of anal fistula tract is one of the surgical options for fistula in ano with encouraging results. Accurate delineation of the fistula tract is prerequisite to achieve a higher rate of healing after fistula surgery. Preservation of nal sphincter funtion is an essential objective in any form of surgical procedures for anal fistula. Larger sample size is needed in order to achieve more significant results.

\section{REFERENCES}

1. Arroyo A, Perez-Legaz J, Moya P, Armananzas L, Lacueva J, Perez-Vicente F, Candela F, Calpena R. Fistulotomy and sphincter reconstruction in the treatment of complex fistula-in-ano: longterm clinical and manometric results 2012; Annals of surgery 255 (5):935-939. doi:10.1097/ SLA.0b013e31824e9112

2. Aboulian A, Kaji AH, Kumar RR. Early result of ligation of the intersphincteric fistula tract for fistula-in-ano. Diseases of the colon and rectum 2011; 54 (3):289-292. doi:10.1007/ DCR.0b013e318203495d

3. Bleier JI, Moloo H. Current management of cryptoglandular fistula-in-ano. World journal of gastroenterology 2011; 17 (28):3286-3291. doi:10.3748/wjg.v17.i28.3286

4. Leng $Q$, Jin $H Y$. Anal fistula plug vs mucosa advancement flap in complex fistula-in-ano: A meta-analysis. World journal of gastrointestinal surgery 2012; 4 (11):256-261. doi:10.4240/ wjgs.v4.i11.256

5. Nicholls RJ. Fistula in ano: an overview. Acta chirurgica lugoslavica 2012; 59 (2):9-13

6. Parks AG, Gordon PH, Hardcastle JD. A classification of fistula-in-ano. The British journal of surgery 1976; 63 (1):1-12

7. Shanwani A, Nor AM, Amri N. Ligation of the intersphincteric fistula tract (LIFT): a sphinctersaving technique for fistula-in-ano. Diseases of the colon and rectum 2010; 53 (1):39-42.

8. Garcia-Aguilar J, Belmonte C, Wong WD, Goldberg SM, Madoff RD. Anal fistula surgery. Factors associated with recurrence and incontinence. Diseases of the colon and rectum 1996; 39 (7):723-729

9. Schouten WR, Zimmerman DD, Briel JW. Transanal advancement flap repair of transsphincteric fistulas. Diseases of the colon and rectum 1999; 42 (11):1419-1422; discussion 1422-1413

10. Hamalainen KP, Sainio AP. Cutting seton for anal fistulas: high risk of minor control defects. Diseases of the colon and rectum 1997; 40 (12):1443-1446; discussion 1447

11. Swinscoe MT, Ventakasubramaniam AK, Jayne DG. Fibrin glue for fistula-in-ano: the evidence reviewed. Techniques in coloproctology 2005; 9 (2):89-94. doi:10.1007/s10151-005-0204-7

12. Hassan M, Zailani M, Md Nor A. Limited fistulectomy and fibrin glue for the treatment of 
complex fistula-in-ano. World Journal of Colorectal Surgery 2009; 1 (1):8

13. Bokhari S, Lindsey I. Incontinence following sphincter division for treatment of anal fistula. Colorectal disease : the official journal of the Association of Coloproctology of Great Britain and Ireland 2010; 12 (7 Online):e135-139. doi:10.1111/j.1463-1318.2009.01872.x

14. Tobisch A, Stelzner S, Hellmich G, Jackisch T, Witzigmann $\mathrm{H}$. Total fistulectomy with simple closure of the internal opening in the management of complex cryptoglandular fistulas: long-term results and functional outcome. Diseases of the colon and rectum 2012; 55 (7):750-755.

15. Paiboon Jivapaisarnpong. Core out fistulectomy, anal sphincter reconstruction and primary repair of internal opening in the treatment of complex anal fistula. J Med Assoc 2009; 92 (5): 638-42

16. Kronborg $\mathrm{O}$. To lay open or excise a fistula-in ano: a randomized trial. Br J Surg 1985; 72:970 